\title{
Olfactory groove meningiomas
}

\author{
Stephen J. Hentschel, M.D., F.R.C.S.(C), and Franco DeMonte, M.D., F.R.C.S.(C) \\ The University of Texas M. D. Anderson Cancer Center, Department of Neurosurgery, Houston, Texas
}

\begin{abstract}
Object. Olfactory groove meningiomas (OGMs) arise over the cribriform plate and may reach very large sizes prior to presentation. They can be differentiated from tuberculum sellae meningiomas because OGMs arise more anterior in the skull base and displace the optic nerve and chiasm inferiorly rather than superiorly.

Methods. The authors searched the neurosurgery database at the M. D. Anderson Cancer Center for cases of OGM treated between 1993 and 2003. The records of these patients were then reviewed retrospectively for details regarding clinical presentation, imaging findings, surgical results and complications, and follow-up status.

Thirteen patients, (12 women and one man, mean age 56 years) harbored OGMs (mean size $5.7 \mathrm{~cm}$ ). All patients underwent bifrontal craniotomies and biorbital osteotomies. There were 11 complete resections (including the hyperostotic bone and dura of the cribriform plate and any extension into the ethmoid sinuses) and two subtotal resections with minimal residual tumor left in patients with recurrent lesions. No complication directly due to the surgery occurred in any patient. There were no recurrences in a mean follow-up period of 2 years (range 0-5 years).

Conclusions. With current microsurgical techniques, the results of OGM resection are excellent, with a high rate of total resection and a low incidence of complications. All hyperostotic bone should be removed with the dura of the anterior skull base to minimize the risk of recurrence.
\end{abstract}

\section{KEY WORDS • meningioma • olfactory groove • complication}

Olfactory groove meningiomas arise over the cribriform plate and frontosphenoid suture and comprise approximately $10 \%$ of intracranial meningiomas. ${ }^{5,15}$ Although these tumors arise in the midline, they may extend predominantly to one side. Extension into the ethmoid sinuses has been reported to occur in $15 \%$ of patients, ${ }^{6}$ although this is probably an underestimate. Further extensions into the nasal cavity and orbit are evident in some cases. The blood supply to these lesions most commonly derives from the anterior and posterior ethmoidal arteries, anterior branches of the middle meningeal artery, and the meningeal branches of the ophthalmic artery. As the tumors become larger, vascular supply from small branches of the ACA and ACoA is not uncommon.,13,16 There are some similarities between TSMs and posteriorly extending OGMs. There are important differences, however (Table 1), particularly in the location of the optic apparatus in relation to the tumor. The optic nerves and chiasm are located inferolateral to OGMs and superolateral to TSMs. ${ }^{11}$ The risk of affecting the optic nerve is also relatively increased when treating meningiomas of the tuberculum sellae region, especially when they exceed $3 \mathrm{~cm}$ in size. ${ }^{4}$

Abbreviations used in this paper: $\mathrm{ACA}=$ anterior cerebral artery; $\mathrm{ACo} \mathrm{A}=$ anterior communicating artery; $\mathrm{CT}=$ computerized tomography; $\mathrm{MR}=$ magnetic resonance; OGM = olfactory groove meningioma; TSM = tuberculum sellae meningioma.

\section{CLINICAL MATERIAL AND METHODS}

\section{Clinical Presentation}

By virtue of their subfrontal location, OGMs may become very large prior to producing symptoms (Fig. 1 left). In the series described by Turazzi, et al., ${ }^{20} 23$ of 37 tumors were greater than $6 \mathrm{~cm}$. Personality changes, such as apathy and akinesia, can be common when the tumors grow to such large sizes and are noticed particularly by family members. Onset of these symptoms is gradual, and they may not be observed early in their course. Other common symptoms include headache and visual deficits. Interestingly, anosmia is noted in hindsight by a significant number of patients, although it is not a common primary complaint. Objective neurological findings, apart from anosmia, are usually limited to visual acuity changes and/ or visual field loss, with true motor paresis being rare. Because the optic nerves and chiasm are compressed superiorly by the tumor, an inferior visual field defect is most common (TSMs present with a bitemporal visual field defect). The Foster-Kennedy syndrome of unilateral optic atrophy and contralateral papilledema, although originally described in OGMs, occurs in only a small number of patients. Table 2 provides a summary of clinical data obtained in our 13 patients as well as in cases reported in five recent series. As expected, OGMs occur most commonly in women in the fifth and sixth decades of life. ${ }^{3}$ 
TABLE 1

Comparison of OGM and TSM*

\begin{tabular}{lll}
\hline \hline \multicolumn{1}{c}{ Factor } & \multicolumn{1}{c}{ OGM } & \multicolumn{1}{c}{ TSM } \\
\hline location & $\begin{array}{c}\text { cribriform, frontosphenoid } \\
\text { suture } \\
\text { ant \& pst ethmoidals, middle } \\
\text { meningeal, ophthalmic } \\
\text { (meningeal branch, ACA \& }\end{array}$ & $\begin{array}{l}\text { planum sphenoidale, } \\
\text { tuberculum sellae } \\
\text { pst ethmoidal (ACA } \\
\text { \& ACoA) } \dagger\end{array}$ \\
& $\begin{array}{l}\text { ACoA) } \dagger \\
\text { olfactory nerves } \\
\text { optic nerve/chiasm }\end{array}$ & $\begin{array}{l}\text { superolat } \\
\text { inferolat }\end{array}$ \\
ACA & pst to posterosuperior & $\begin{array}{l}\text { inferolat } \\
\text { superolat } \\
\text { posterosuperior }\end{array}$ \\
\hline
\end{tabular}

* Pst $=$ posterior.

$\dagger$ When the tumor becomes large in size.

\section{Imaging Features}

The appearance of OGMs on CT and MR imaging is similar to meningiomas situated elsewhere. Computerized tomography scanning is particularly useful for defining the osseous anatomy, including areas of hyperostosis or erosion that may assist in the diagnosis or planning of a surgical approach to these lesions. Meningiomas typically appear slightly hyperdense relative to the brain parenchyma on noncontrast CT scans and enhance homogeneously and brightly after administration of contrast. Paranasal sinus extension through the floor of the anterior cranial fossa is well demonstrated on CT scans, particularly on coronal views. Both MR imaging and MR angiography will define the relationship of the tumor to the optic nerves and chiasm as well as the ACAs and communicating complex. Catheter angiography is generally not required. Meningiomas commonly appear isointense to gray matter on $\mathrm{T}_{1}$-weighted sequences and iso- or hyperintense on $\mathrm{T}_{2}$ weighted sequences. Dense enhancement after administration of $\mathrm{Gd}$ is also seen.

\section{Management Options}

Many OGMs are quite large on initial presentation, and in these cases surgery may be the only option. Continued observation, however, may play a role in asymptomatic patients who are very elderly, unable to withstand surgery, or who harbor small incidental tumors.

\section{Surgical Approach}

The most common surgical approaches are variants of either the standard pterional ${ }^{8,9,18,20}$ or subfrontal ${ }^{2,4,7}$ exposures, although some authors have advocated an interhemispheric approach. ${ }^{13}$ When considering any approach, the following maneuvers must be possible: early interruption of the blood supply to the tumor; nontraumatic separation of the frontal lobes from the tumor; dissection of the ACAs, optic nerves, and chiasm; and excellent visualization of the anterior cranial fossa floor to permit tumor resection and repair of defects. ${ }^{13}$ The advantages of the pterional and subfrontal approaches are summarized in Table 3. The subfrontal approach may incorporate a unior bifrontal craniotomy and orbital osteotomies. We will describe our surgical approach to these tumors; this approach may be used to treat most OGMs larger than $3 \mathrm{~cm}$.
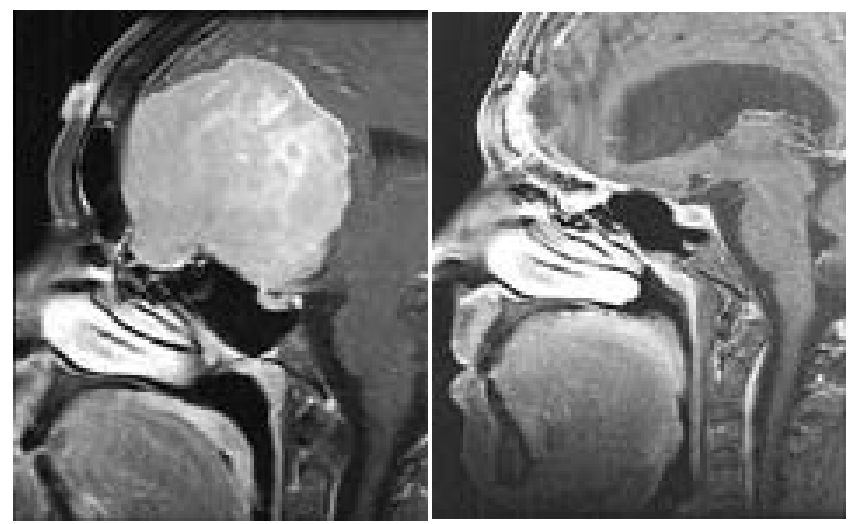

Fig. 1. Left: Sagittal $\mathrm{T}_{1}$-weighted contrast-enhanced MR image of an OGM obtained in a 43-year-old woman who presented with a 1-year history of progressive apathy, lethargy, and unilateral visual loss. The tumor extends into the ethmoid sinus and measures $7 \times 6.8 \times 6.8 \mathrm{~cm}$. Right: Postoperative sagittal $\mathrm{T}_{1}$-weighted contrast-enhanced MR image obtained in the same patient. The tumor, including the component extending into the ethmoid sinuses, has been completely resected.

The patient is placed supine on the operating table with the head fixated in pins. A bicoronial skin incision is fashioned that extends from zygomatic arch to zygomatic arch. It is critical to dissect in the immediate subgaleal plane when elevating the scalp flap so as to preserve as thick and as well vascularized a pericranial flap as possible. The posterior aspect of the scalp flap is undermined to maximize the length of the pericranial flap. The pericranial flap is then elevated separately from the scalp. The supraorbital neurovascular bundles are freed from their foramen.

Although a unilateral craniotomy is adequate for smaller tumors, bilateral access is desirable for larger tumors and a bilateral frontal craniotomy is performed. Burr holes are placed bilaterally at the key hole as well as on both sides of the superior sagittal sinus at the posterior limit of the craniotomy. The keyhole burr holes should also enter the orbit so as to allow for easy access when performing the orbital osteotomies. Following elevation of the bifrontal craniotomy, the frontal sinus is demucosalized and cranialized. A bilateral orbital osteotomy is then performed making cuts at the frontozygomatic and frontonasal sutures. The crista galli is identified and removed. A subperiosteal orbital dissection is performed and the anterior and posterior ethmoidal arteries are coagulated and divided (Fig. 1 right). ${ }^{14}$ The dura is opened linearly along the frontal poles, and the sagittal sinus is ligated and divided along with the falx just above the crista galli. Division of the superior sagittal sinus at this very anterior point is of no consequence.

With the division of the ethmoidal arteries, the majority of the blood supply to the tumor has been interrupted. Small meningeal feeding arteries that are still present can be divided as the dissection proceeds along the floor of the anterior cranial fossa, thus further devascularizing the tumor. The tumor can then be centrally debulked using an ultrasonic aspirator and the tumor capsule dissected. Even in large tumors, the posterior arachnoidal membranes typically remain intact and there is usually a reasonable plane 
TABLE 2

Comparison of clinical data for five recent series and the M. D. Anderson series of olfactory groove meningiomas*

\begin{tabular}{lcccrrrr}
\hline \hline \multicolumn{1}{c}{ Authors \& Year } & $\begin{array}{c}\text { No. of } \\
\text { Cases }\end{array}$ & $\begin{array}{c}\text { Age Range in } \\
\text { Years (mean) }\end{array}$ & $\begin{array}{c}\text { Female/ } \\
\text { Male }\end{array}$ & Headache & $\begin{array}{c}\text { Mental } \\
\text { Changes }\end{array}$ & $\begin{array}{c}\text { Visual } \\
\text { Loss }\end{array}$ & \begin{tabular}{c} 
Anosmia \\
\hline Mayfrank \& Gilsbach, 1996
\end{tabular} \\
Paterniti, et al., 1999 & 18 & $45-75$ & $13: 5$ & NA & $10(56)$ & $4(22)$ & $11(61)$ \\
Tsikoudas \& Martin-Hirsch, 1999 & 20 & $4-73(49)$ & $15: 5$ & NA & NA & NA & NA \\
Turazzi, et al., 1999 & 13 & $34-74$ & $10: 3$ & $8(62)$ & $8(62)$ & $4(31)$ & $7(54)$ \\
Zevgaridis, at al., 2001 & 37 & $32-64(57)$ & $22: 15$ & NA & $27(73)$ & $16(43)$ & $27(73)$ \\
present series, 2003 & 5 & $55-67(63)$ & $2: 3$ & NA & NA & $5(100)$ & NA \\
total $\dagger$ & 13 & $40-72(56)$ & $12: 1$ & $5(38)$ & $9(69)$ & $6(46)$ & $8(62)$ \\
\hline
\end{tabular}

* Results may have been taken from a larger series in which there were multiple tumor locations and specific details regarding OGMs that may not have been reported. Abbreviation: NA = not available.

$\dagger$ Percentages reflect total number in series in which the information was available.

between the tumor, the optic nerve and chiasm, and the ACAs (Video). There may be small feeding vessels from the ACoA complex and from the $\mathrm{A}_{2}$ segments of the ACAs. Although these small feeding vessels can be sacrificed, it is critical to follow them carefully to ensure they are not perforating vessels. Preservation of these perforators, which supply the optic nerve and chiasm and hypothalamus, is vital. If dissection of the tumor off of these perforators is difficult, it is better to leave a small amount of tumor behind rather than create an infarct due to operative injury.

Click here to view video clip: Dissection of the meningioma off of the optic nerves, chiasm, and ACA complex. Note the presence of a clear and distinct arachnoidal plane between the tumor and the optic nerves and chiasm and the ACAs.

After tumor resection, the dura of the floor of the anterior cranial fossa should be resected with any hyperostotic bone. ${ }^{1}$ Tumor extending into the ethmoid sinuses, nasal cavity, and orbits is removed. Ethmoidal sinus extension was observed in six (46\%) of 13 patients in our series. The dura is repaired in a watertight fashion by using free pericranial tissue, fascia lata, or an allograft substitute. The pericranial flap, which is excellently vascularized, is an ideal material for the repair of the anterior cranial base. This is brought down over the floor of the anterior cranial fossa and sutured posteriorly to holes drilled in the planum sphenoidale. The orbital osteotomy and bone flap are plated back in position, careful not to compress the pericranial flap. ${ }^{12}$

TABLE 3

Advantages of the pterional and subfrontal approaches when resecting $O G M S$

Approach \& Advantage

\begin{tabular}{l}
\hline \hline Approach \& Advantage \\
\hline pterional \\
early visualization of optic apparatus \& ACAs \\
less retraction on frontal lobe (if orbital osteotomies not added to sub- \\
frontal approach) \\
avoids entry into frontal sinus \\
subfrontal \\
direct access to cranial base permitting devascularization \& resection \\
easier access to ethmoidal arteries w/in orbit \\
easier to repair cranial base w/ pericranial flap \\
\hline
\end{tabular}

\section{RESULTS}

The results of OGM resection were quite good. There were high rates of complete resection and improvement in signs and symptoms, and few reported complications. Table 4 lists the results obtained in our 13 patients and those reported on in five recent series. The patients in our series underwent surgery during a 10-year period (19932003). Two patients underwent emergency surgery when progressive neurological deficits and visual deterioration were observed.

\section{DISCUSSION}

The large size of many of these tumors makes resection challenging. Nearly $50 \%$ of the tumors in our series were larger than $6 \mathrm{~cm}$ in diameter, whereas greater than $60 \%$ of the tumors in the series by Turazzi, et al., ${ }^{20}$ were larger than $6 \mathrm{~cm}$ in diameter. Despite this large size, all nonrecurrent tumors in our series were completely resected (Fig. 2). ${ }^{17,19,20}$ This is partly due to the fact that the arachnoid membrane separating these lesions from nearly all the vital neurovascular structures is left intact, even when treating very large tumors, thus facilitating dissection.

Treatment of patients with longstanding visual loss or mental status changes due to OGMs is frequently satisfying because the likelihood is high that improvement will occur and the personality status will return to normal. All patients with mental status changes in this series and in that reported by Turazzi, et al., improved, and all but one patient in our series experienced visual improvement (all patients in the series by Turazzi, et al., had visual improvement) (Table 4). This patient suffered delayed-onset visual function deterioration postoperatively, which was believed to be due to vasospasm of the perforating vessels manipulated during resection. The deficit responded to blood pressure elevation and therapy with calcium channel blockers, and the patient regained her preoperative level of vision (20/30 acuity bilaterally).

With current microsurgical techniques, the complication rates associated with resection of OGMs is very low (Table 5). In our series and those reported by Paterniti, et al. ${ }^{17}$ and Turazzi, et al., ${ }^{20}$ there were no postoperative complications. No patient in our series experienced permanent visual worsening. Complications such as cerebrospinal fluid leakage, infection, seizures, and decreased 


\section{S. J. Hentschel and F. DeMonte}

TABLE 4

Results of surgical resection in recent series of olfactory groove meningiomas

\begin{tabular}{|c|c|c|c|c|c|c|c|c|}
\hline \multirow[b]{2}{*}{ Authors \& Year } & \multirow[b]{2}{*}{ Approach } & \multirow[b]{2}{*}{$\begin{array}{l}\text { No. of } \\
\text { Cases }\end{array}$} & \multirow[b]{2}{*}{ Mean Size $(\mathrm{cm})$} & \multirow[b]{2}{*}{$\begin{array}{c}\text { Complete } \\
\text { Resection (\%) }\end{array}$} & \multicolumn{2}{|c|}{ Improved Dysfunction (\%) } & \multirow[b]{2}{*}{$\begin{array}{l}\text { Recur- } \\
\text { rence }\end{array}$} & \multirow[b]{2}{*}{$\begin{array}{l}\text { Follow } \\
\text { Up (yrs) }\end{array}$} \\
\hline & & & & & $\begin{array}{l}\text { Mental } \\
\text { Status }\end{array}$ & Vision & & \\
\hline Mayfrank \& Gilsbach, 1996 & interhemispheric & 18 & $1.5-7.0$ & $18(100)$ & NA & NA & NA & NA \\
\hline Paterniti, et al., 1999 & pterional & 20 & NA & $20(100)$ & NA & NA & 0 & $1-21$ \\
\hline Tsikoudas \& Martin-Hirsch, 1999 & bifrontal & 13 & $8>6$ & NA & NA & NA & 4 & NA \\
\hline Turazzi, et al., 1999 & pterional & 37 & $23>6$ & $37(100)$ & $27(100)$ & $16(100)$ & 0 & $4(1-8)$ \\
\hline Zevgaridis, et al., 2001 & frontal & 5 & 6.7 (range $5.5-8)$ & $5(100)$ & NA & $4(80)$ & NA & $5(2-8)$ \\
\hline present series, $2003^{*}$ & bifrontal, biorbital & 13 & 5.6 (range $3.5-8)$ & $11(85)$ & $9(100)$ & $5(83)$ & 0 & $2(0-5)$ \\
\hline total & & 106 & $6.0($ range $3.5-8)$ & $91(98)$ & $36(100)$ & $25(93)$ & 4 & $4(1-8)$ \\
\hline
\end{tabular}

* Includes two patients with recurrent tumors that were incompletely resected.

visual acuity, much more common in the past, are becoming infrequent. Five of our 13 patients received a blood transfusion ( $2 \mathrm{U}$ each), including the two patients with recurrent tumors.

During the resection of OGMs, it may be possible to preserve one or even both of the olfactory nerves (Fig. 3). In their series of 12 patients with OGMs (size range 2-5.5 $\mathrm{cm})$ Welge-Luessen, et al., ${ }^{21}$ reported that it was possible to preserve at least one of the olfactory nerves in two cases. Despite the anatomical preservation, however, there

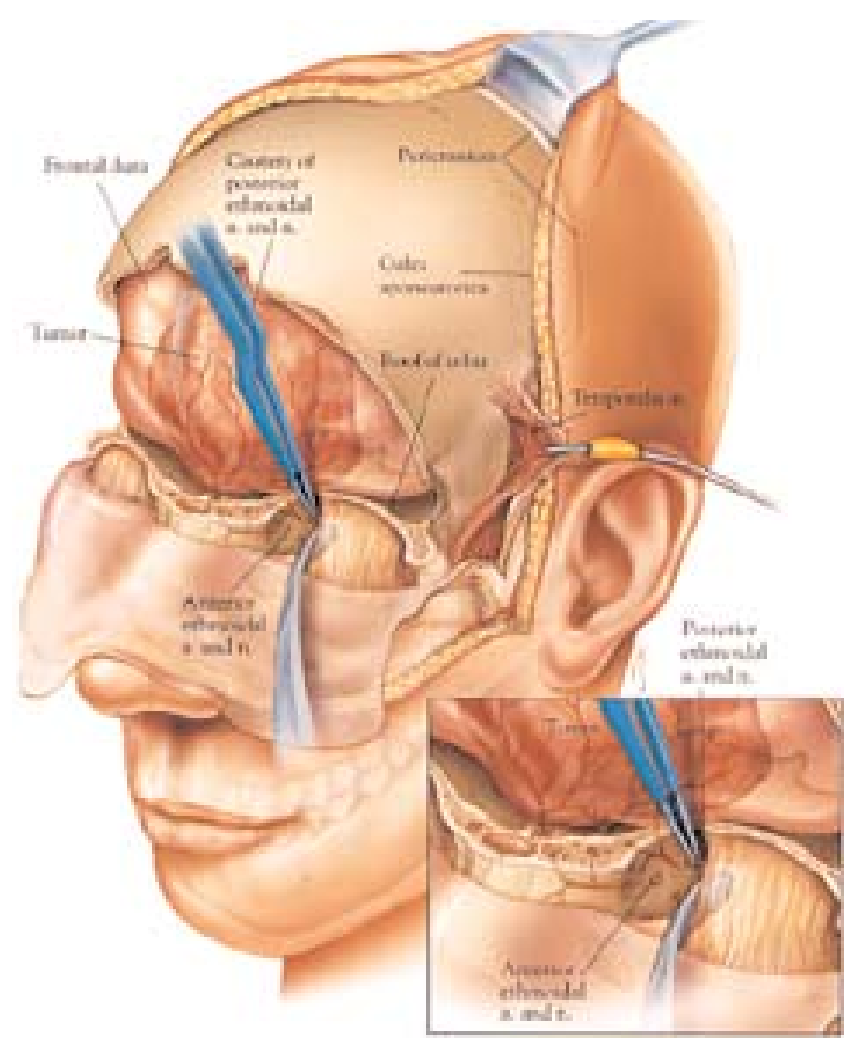

Fig. 2. Interruption of the blood supply to OGMs. A bifrontal craniotomy has been performed with bilateral orbital osteotomies. A subperiosteal orbital dissection is performed and the anterior and posterior ethmoidal arteries are coagulated and cut bilaterally (see inset). $a=$ artery $n=$ nerve. was no evidence of olfactory function on that side in either patient. They concluded that preservation of olfactory function was likely if preoperative function was normal and if the tumor was smaller than $3 \mathrm{~cm}$ in diameter.

In a series of 13 patients with OGMs, Tsikoudas and Martin-Hirsch ${ }^{19}$ reported on four patients in whom tumors recurred, respectively, at 3, 9, 10, and 11 years postoperatively. All had undergone what was believed to be complete resection at the first surgery. In a detailed analysis of the factors affecting the meningioma recurrence, Mirimanoff, et al., ${ }^{15}$ identified OGMs as being associated with a high rate of complete resection $(77 \%)$ but a rather high rate of recurrence (30 and $41 \%$ at 5 and 10 years, respectively). They found that extent of resection and tumor location were important factors in predicting the recurrence. In the case of OGMs, recurrence can be minimized by aggressive resection of the anterior cranial fossa dural floor and drilling of the involved bone. ${ }^{1}$

Indices of MIB-1 labeling for OGMs specifically are not widely reported. The median MIB-1 labeling index in the M. D. Anderson series was $4.9 \%$ with a maximum of $13.8 \%$ (in two other patients the labeling index was $\geq 10$ ). In a recent study of meningiomas completely resected in various locations, investigators found no recurrences in 52 cases followed for 10 years in patients with a MIB-1 labeling index of less than 10 , whereas 30 of 31 patients with a labeling index of 10 or greater developed recurrent tumors within 10 years, $71 \%$ of these within 5 years. ${ }^{10}$

TABLE 5

Complications of surgery for OGMs*

\begin{tabular}{|c|c|c|c|c|c|c|}
\hline Authors \& Year & $\begin{array}{l}\text { No. of } \\
\text { Cases }\end{array}$ & $\begin{array}{l}\text { Visual } \\
\text { Loss }\end{array}$ & $\begin{array}{l}\text { CSF } \\
\text { Leak }\end{array}$ & $\begin{array}{l}\text { Infec- } \\
\text { tion }\end{array}$ & $\begin{array}{l}\text { Sei- } \\
\text { zure }\end{array}$ & $\begin{array}{l}\text { In- } \\
\text { farct }\end{array}$ \\
\hline $\begin{array}{l}\text { Mayfrank \& } \\
\text { Gilsbach, } 1996\end{array}$ & 15 & 0 & 0 & 1 & 0 & 1 \\
\hline Paterniti, et al., 1999 & 20 & 0 & 0 & 0 & 0 & 0 \\
\hline $\begin{array}{l}\text { Tsikoudas \& } \\
\text { Martin-Hirsch, } 1999\end{array}$ & 13 & 1 & 3 & 1 & 1 & 0 \\
\hline Turazzi, et al., 1999 & 37 & 0 & 0 & 0 & 0 & 0 \\
\hline Zevgaridis, et al., 2001 & 5 & NA & NA & NA & NA & NA \\
\hline present series, 2003 & 13 & 0 & 0 & 0 & 0 & 0 \\
\hline total & 106 & 1 & 3 & 2 & 1 & 1 \\
\hline
\end{tabular}

$*$ CSF $=$ cerebrospinal fluid. 


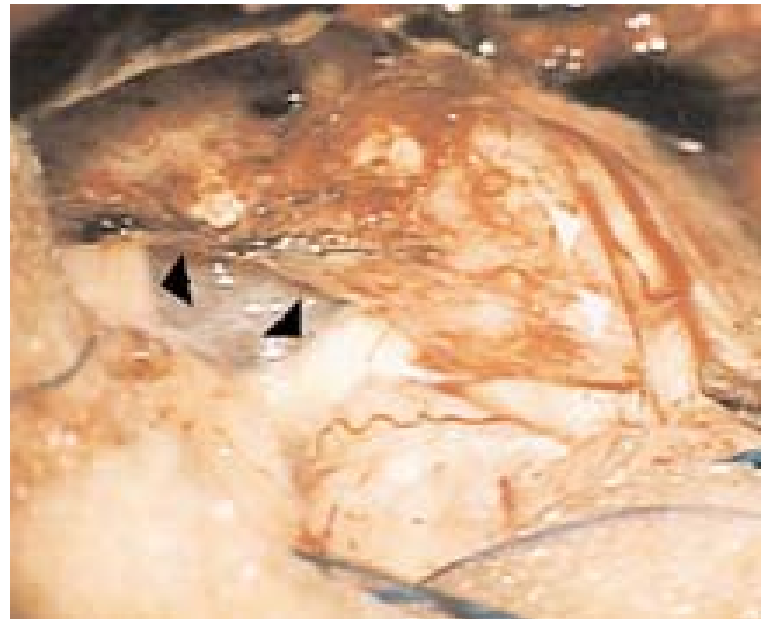

Fig. 3. Intraoperative site at the completion of OGM resection. The optic nerves (black arrowheads) and the right olfactory nerve (white arrowheads) are well visualized and completely preserved in this patient who harbored a 3.5-cm OGM.

\section{CONCLUSIONS}

Despite the fact that OGMs may become very large and present with longstanding symptoms and signs, resection provides very satisfying results, both for the patient and surgeon. There is a high rate of improvement in neurological function and a low incidence of complications.

\section{Acknowledgment}

All images and video are the property of the Department of Neurosurgery, University of Texas M. D. Anderson Cancer Center and are used with permission.

\section{References}

1. Al-Mefty O: Operative Atlas of Meningiomas. Philadelphia: Lippincott-Raven, 1998, pp 1-66

2. Babu R, Barton A, Kasoff SS: Resection of olfactory groove meningiomas: technical note revisited. Surg Neurol 44: 567-572, 1995

3. Black PM: Meningiomas. Neurosurgery 32:643-657, 1993

4. DeMonte F: Surgical treatment of anterior basal meningiomas. J Neurooncol 29:239-248, 1996

5. DeMonte F, Marmor E, Al-Mefty O: Meningiomas, in Kaye A, Laws E Jr. (eds): Brain Tumors: An Encyclopedic Approach, ed 2. London: Churchill Livingstone, 2001, pp 719-750

6. Derome PJ, Guiot G: Bone problems in meningiomas invading the base of the skull. Clin Neurosurg 25:435-451, 1978

7. El Gindi S: Olfactory groove meningioma: surgical techniques and pitfalls. Surg Neurol 54:415-417, 2000
8. Hassler W, Zentner J: Pterional approach for surgical treatment of olfactory groove meningiomas. Neurosurgery 25:942-947, 1989

9. Hassler W, Zentner J: Surgical treatment of olfactory groove meningiomas using the pterional approach. Acta Neurochir Suppl 53:14-18, 1991

10. Ho DM, Hsu CY, Ting LT, et al: Histopathology and MIB-1 labeling index predicted recurrence of meningiomas: a proposal of diagnostic criteria for patients with atypical meningioma. Cancer 94:1538-1547, 2002

11. Jallo GI, Benjamin V: Tuberculum sellae meningiomas: microsurgical anatomy and surgical technique. Neurosurgery 51: 1432-1440, 2002

12. Jensen R, McCutcheon IE, DeMonte F: Postoperative swelling of pericranial pedicle graft producing intracranial mass effect. Report of two cases. J Neurosurg 91:124-127, 1999

13. Mayfrank L, Gilsbach JM: Interhemispheric approach for microsurgical removal of olfactory groove meningiomas. $\mathbf{B r} \mathbf{J}$ Neurosurg 10:541-545, 1996

14. McDermott MW, Rootman J, Durity FA: Subperiosteal, subperiorbital dissection and division of the anterior and posterior ethmoid arteries for meningiomas of the cribriform plate and planum sphenoidale: technical note. Neurosurgery 36: 1215-1219, 1995

15. Mirimanoff RO, Dosoretz DE, Linggood RM, et al: Meningioma: analysis of recurrence and progression following neurosurgical resection. J Neurosurg 62:18-24, 1985

16. Ojemann RG: Olfactory groove meningiomas, in Al-Mefty O (ed): Meningiomas. New York: Raven Press, 1991, pp 383-393

17. Paterniti S, Fiore P, Levita A, et al: Basal meningiomas. A retrospective study of 139 surgical cases. J Neurosurg Sci 43: 107-114, 1999

18. Paterniti S, Fiore P, Levita A, et al: Venous saving in olfactory meningioma's surgery. Clin Neurol Neurosurg 101:235-237, 1999

19. Tsikoudas A, Martin-Hirsch DP: Olfactory groove meningiomas. Clin Otolaryngol 24:507-509, 1999

20. Turazzi S, Cristofori L, Gambin R, et al: The pterional approach for the microsurgical removal of olfactory groove meningiomas. Neurosurgery 45:821-826, 1999

21. Welge-Luessen A, Temmel A, Quint C, et al: Olfactory function in patients with olfactory groove meningioma. J Neurol Neurosurg Psychiatry 70:218-221, 2001

22. Zevgaridis D, Medele RJ, Muller A, et al: Meningiomas of the sellar region presenting with visual impairment: impact of various prognostic factors on surgical outcome in 62 patients. Acta Neurochir 143:471-476, 2001

Manuscript received April 16, 2003.

Accepted in final form May 8, 2003.

Address reprint requests to: Franco DeMonte, M.D., F.R.C.S.(C), Department of Neurosurgery, University of Texas M. D. Anderson Cancer Center, 1515 Holcombe Boulevard, Box 442, Houston, Texas 77030-4009. email: fdemonte@mdanderson.org. 